\title{
Thermal Properties of Electrospun Polyesters
}

\author{
Jong-Sang KIM and Dai Soo LEE ${ }^{\dagger}$ \\ Faculty of Chemical Engineering and Technology, College of \\ Engineering, Chonbuk National University, Chonju 561-756, Korea
}

(Received September 20, 1999)

\begin{abstract}
KEY WORDS Electrospinning / Poly(ethylene terephthalate)/ Poly(ethylene naphthalate)/ Thermal Property / Exchange Reaction / Blends /
\end{abstract}

Ultrafine fibers of very small diameter are useful for filtration of submicron particles, cleaning glass, and wound dressing in medicine. After Formhals invented a process and appratus for the production of polymeric filaments using electrostatic force, ${ }^{1}$ electrospinning was studied to manufature ultrafine fibers. ${ }^{2-7}$ Electrospinning produces ultrafine fibers conveniently by electrical force on the droplets of polymer solution or melts employing an equipment depicted in Figure 1. When the electrical force equals the force of surface tension at the surface of polymer solution or melts, a charged droplet hanging at the end of capillary tube is in equilibrium. Increasing the electrical potential overcomes the surface tension, makes the charged drop unstable, and forms charged jets. Finally, ultrafine fibers are spun and collected on an electrically grounded screen.

Most of previous studies for electrospinning are on the manufacture of ultrafine fibers. As far as we know, there are few reports on the thermal properties of the polymers after electrospinning. Understanding thermal properties of electrospun fibers is important for various applications of the fibers. Recently, we carried out electrospinning of poly(ethylene terephthalate) (PET), poly(ethylene naphthalate) (PEN), and PET/PEN blends and thermal properties of the polyesters after electrospinning are reported in this paper.

\section{EXPERIMENTAL}

Commercial polymers were used in this study and characteristics of the polymers are given in Table I. Blends of PET and PEN were prepared with a twin screw extruder at $290^{\circ} \mathrm{C}$. Electrospinning of PET, PEN, and PET/PEN blends in melts were carried out by the appratus in Figure 1. The electrospinning temperatures of PET and PEN or the PET/PEN blends were $270^{\circ} \mathrm{C}$ and $290^{\circ} \mathrm{C}$ respectively. The polymers were kept in a molten state in air during electrospinning for $c a .2 \mathrm{~h}$. Ultrafine fibers whose diameters were submicrons were obtained from the polyesters by electrospinning. Thermal properties of the polymers before and after electrospinning were studied by differential scanning calorimeter (DSC) (DSC 910 from DuPont Instruments equipped with TA 2000) and thermogravimetric analyzer (TGA) (TGA 951 from DuPont Instruments equipped with TA 2000). To

\footnotetext{
${ }^{\dagger}$ To whom correspondence should be addressed.
}

control the thermal history of the samples, all samples were heated to $300^{\circ} \mathrm{C}$, maintained for $3 \mathrm{~min}$, and then quenched with liquid nitrogene in DSC. The quenched samples were reheated to $300^{\circ} \mathrm{C}$ at $10^{\circ} \mathrm{C} \mathrm{min}^{-1}$. Thermal characterization was carried out under nitrogen gas flow. Intrinsic viscosities (I.V.s) of PET and PEN before and after electrospinning were determined using trifluoroacetic acid as solvent at $25^{\circ} \mathrm{C}$ as a measure of molecular weight change.

\section{RESULTS AND DISCUSSION}

In Figure 2, DSC thermograms of polyesters before electrospinning are shown. All the polyesters showed decrease of specific heats due to glass transition of amorphous phase and exotherms and endotherms due to crystallization and melting of crystalline phase. The numbers in the Figures denote glass transition temperature

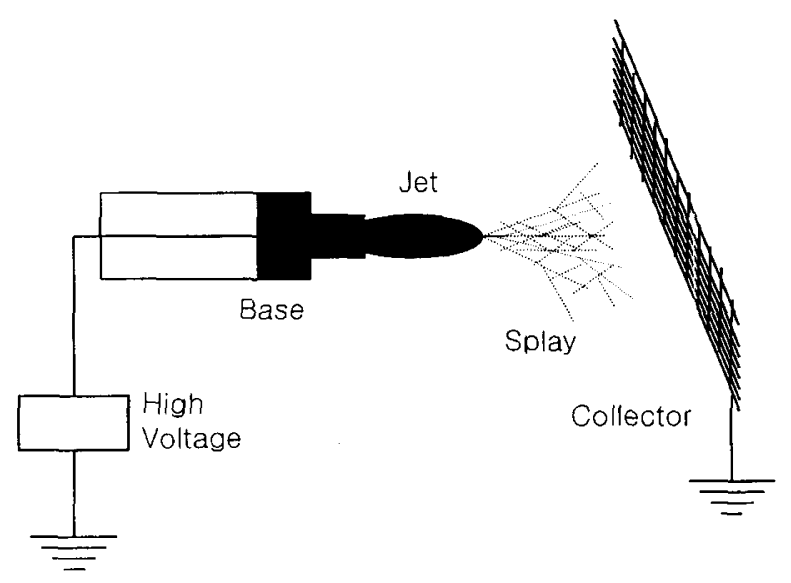

Figure 1. Diagram of electrospinning appratus.

Table I. Characteristics of raw materials

\begin{tabular}{lll}
\hline Material & \multicolumn{1}{c}{ Manufacturer } & \multicolumn{1}{c}{ Characteristics } \\
\hline PET & Eastman Chemical & $\begin{array}{l}\text { Number average molecular } \\
\text { weight: } 2.4 \times 10^{4} \\
\text { Weight average molecular } \\
\end{array}$ \\
& & weight: $4.6 \times 10^{4}$ \\
PEN & Shell Co. & Number average molecular \\
& & weight: $2.4 \times 10^{4}$ \\
& & Weight average molecular \\
& weight: $4.8 \times 10^{4}$ \\
\hline
\end{tabular}




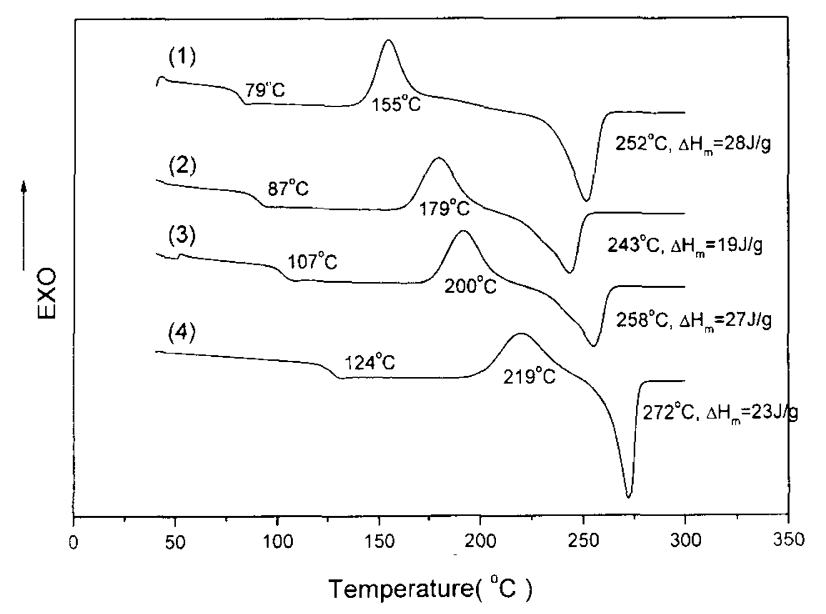

Figure 2. DSC thermograms of various polyesters: (1)PET; (2) PET/PEN (75/25 by wt.) blends; (3)PET/PEN(25/75 by wt.) blends; (4)PEN.

$\left(T_{\mathrm{g}}\right)$, crystallization peak temperature $\left(T_{\mathrm{c}}\right)$, crystalline melting peak temperature $\left(T_{\mathrm{m}}\right)$, and heat of crystalline melting $\left(\Delta H_{\mathrm{m}}\right)$. According to Aoki and his coworkers, PET/PEN blends undergo exchange reaction easily during melt mixing. ${ }^{8} T_{\mathrm{m}}$ of the PET/PEN blends are lower than those of PET and PEN. According to Yamadera and Park, ${ }^{9,10}$ exchange reactions of polyester blends lower the crystallinity and $T_{\mathrm{m}} \mathrm{s}$. PET/PEN blends possibly also underwent exchange reaction during melt mixing and structural irregularity introduced in the polyester chains due to exchange reactions lowered the $T_{\mathrm{m}} \mathrm{s}$.

Figure 3 shows DSC thermograms of PET and PEN respectively after electrospinning at different voltages. $T_{\mathrm{g}} \mathrm{s}$ and $T_{\mathrm{c}} \mathrm{S}$ of PET and PEN were lowered while $T_{\mathrm{m}} \mathrm{s}$ were almost constant compared with those of PET and PEN before electrospinning. The DSC thermograms in Figure 3 were obtained after heating of electrospun fibers above $T_{\mathrm{m}} \mathrm{s}$ and quenching with liquid nitrogene in DSC to control the thermal histories of the sample. Therefore, change of thermal properties of PET and PEN in Figure 3 is attributable to the change of thermal properties after electrospinning. Peak area of cold crystallization is substantially smaller than that of melting, indicating the samples were not properly quenched and therefore partially crystallized during elimination of thermal history. Thus, increase of the $\Delta H_{\mathrm{m}}$ of the PET and the PEN is speculated to result from relatively easy crystallization of the polymers after electrospinning. The decrease of $T_{\mathrm{g}}$ and $T_{\mathrm{c}}$ and increase of $\Delta H_{\mathrm{m}}$ of polyesters after electrospinning imply increase of segmental mobility. Segmental mobilities of homopolymers are determined by molecular weight and chain entanglements. According to Adam et al., ${ }^{11}$ TGA data refelect different thermal degradation depending on molecular weights of polymers. We compared thermal degradation of PET before electrospinning with that of PET after electrospinning employing TGA and thermograms obtained are shown in Figure 4. In Figure 4, the thermogram of the PET is hardly affected by electrospinning. We measured I.V.S of PET and PEN before and after electrospinning to check change of molecular weights. I.V. of PET decreased from $0.687 \mathrm{dL} \mathrm{mg}^{-1}$ to $0.388 \mathrm{dL} \mathrm{mg}^{-1}$ and that

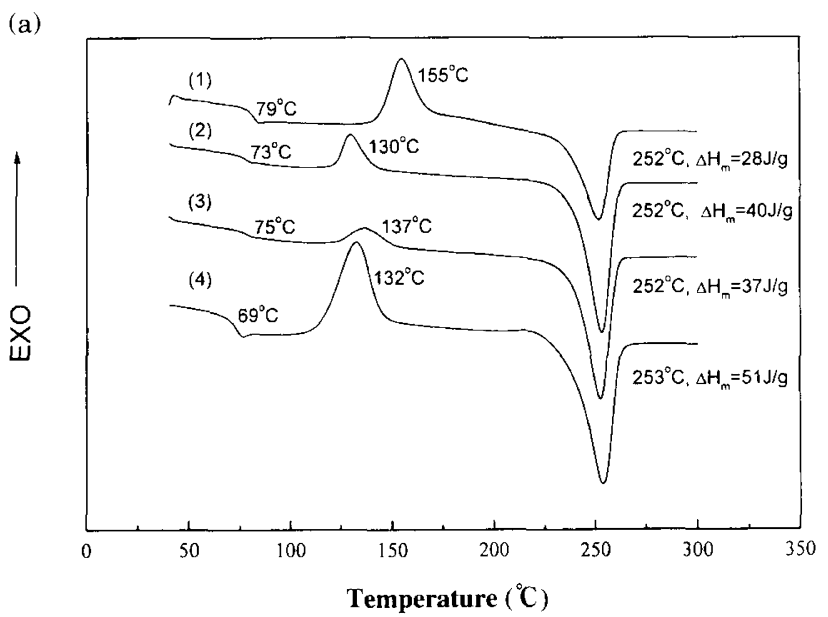

(b)

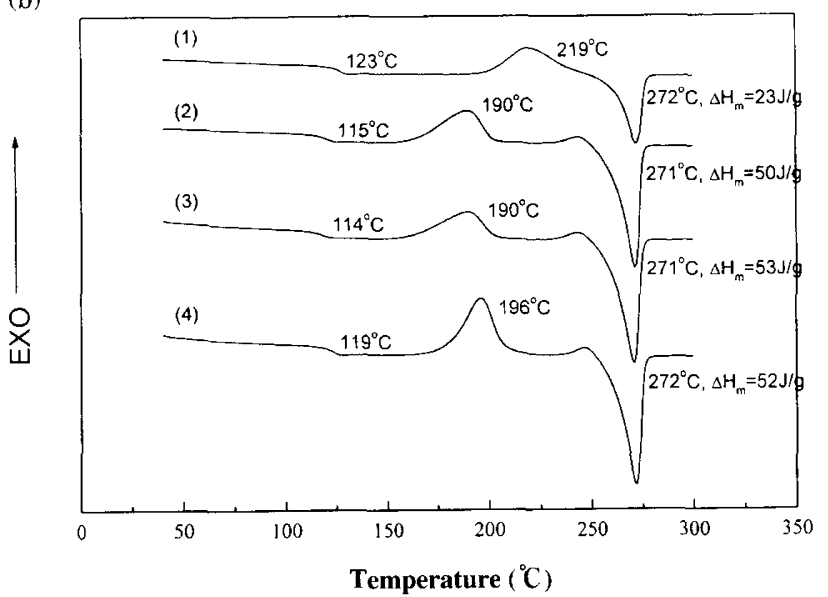

Figure 3. DSC thermograms of PET(a) and PEN(b) after electrospinning at different voltages $(\mathrm{kV})$ : (1)Raw polymers before electrospinning; (2)10; (3)13; (4)15.

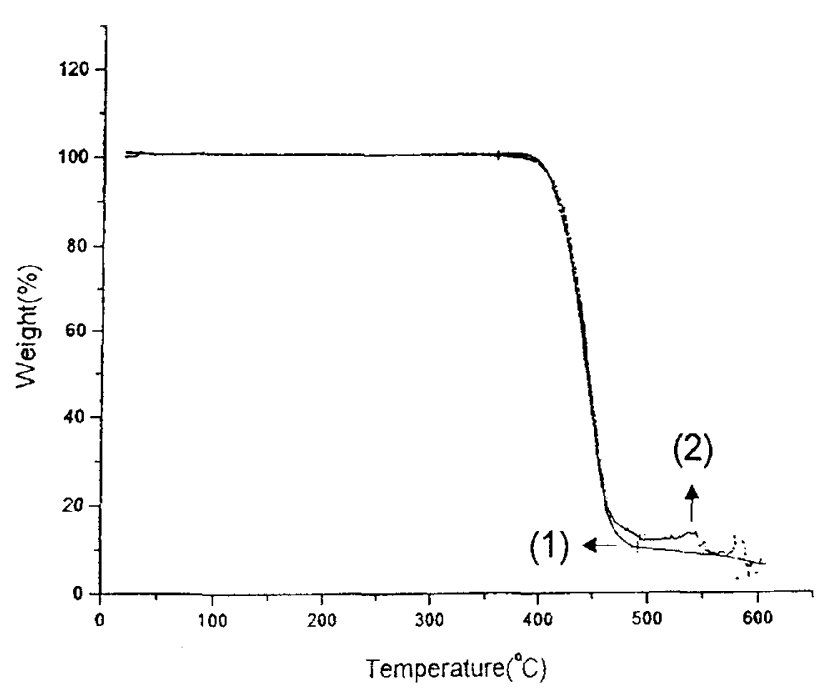

Figure 4. TGA thermograms of PETs before electrospinning (1) and after electrospinning (2).

of PEN decreased from $0.68 \mathrm{dL} \mathrm{mg}^{-1}$ to $0.423 \mathrm{dL} \mathrm{mg}^{-1}$ at $25^{\circ} \mathrm{C}$ in trifluoroacetic acid. TGA thermograms are not so sensitive to change of molecular weight of polyesters. It seems that change of thermal properties in Figure 3 

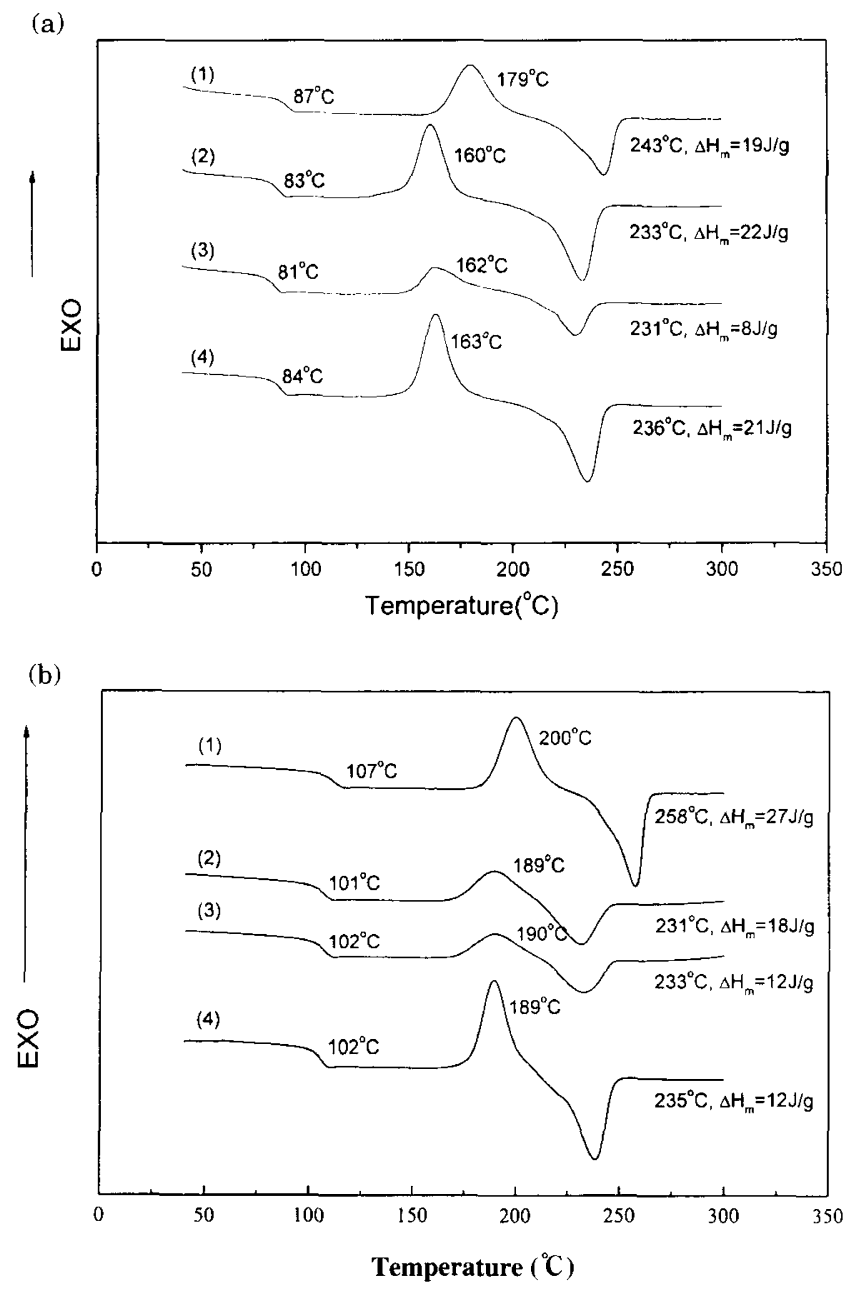

Figure 5. DSC thermograms of PET/PEN (75/25 by wt.) blends (a) and PET/PEN (25/75 by wt.) (b) after electrospinning at different voltages $(\mathrm{kV})$ : (1)Raw polymers before electrospinning; (2)10; (3)13; (4)15.

was primarily due to decrease of I.V.s, i.e., decrease of molecular weights. It is not clear if decrease of I.V.s after electrospinning was due to high electrical force applied or thermal degradation in melts at this moment. Decrease of I.V.S of PET and PEN may result from thermal degradation as polyesters are susceptible to thermal degradation in melts generally. It is postulated that decrease of molecular weights resulted in decrease of chain entanglements and lowered $T_{\mathrm{g}} \mathrm{s}$ and $T_{\mathrm{c}} \mathrm{s}$ and increased $\Delta H_{\mathrm{m}} \mathrm{s}$ of PET and PEN as the segmental mobilities of polymers increased.
Figure 5 shows DSC thermograms of PET/PEN blends after electrospinning at different voltages. $T_{\mathrm{g}} \mathrm{s}, T_{\mathrm{c}} \mathrm{s}$, and $T_{\mathrm{m}} \mathrm{s}$ of the PET/PEN blends were lowered compared with those of PET/PEN blends before electrospinning. $T_{\mathrm{m}} \mathrm{s}$ of the blends after electrospinning were lower than those of the blends before electrospinning. It seems that electrospinning in melts results in more irregular molecular architecture due to further exchange reactions in melts during electrospinning and lower the $T_{\mathrm{m}} \mathrm{s}$. This might be due to thermal treatment of polymer melts during electrospinning, not because of electrospinning itself. Electrospinning voltage does not affect thermal properties of polymers in experimental ranges.

\section{CONCLUSION}

Electrospinning of polymers resulted in increase of crystallinity and decrease of $T_{\mathrm{g}} \mathrm{s}$ and $T_{\mathrm{c}} \mathrm{s}$ of PET and PEN. Thermal property change of electrospun neat polyesters primarily resulted from decrease of molecular weight after electrospinning by thermal degradation. However, change of thermal properties of PET/PEN blends after electrospinning was attributable to exchange reactions of PET and PEN in melt blends.

Acknowledgment. This work was supported by the Korea Science and Engineering Foundation (Post-Doc program for Jong-Sang Kim and 97-05-02-02-01-3) and Research Institute of Advanced Materials Development of Chonbuk National University.

\section{REFERENCES}

1. A. Formhals, U. S. Patent, 1975504 (1934),

2. L. Larrondo and R. St. J. Manley, J. Polym. Sci., Polym. Phys. Ed., 19, 909 (1981).

3. L. Larrondo and R. St. J. Manley, J. Polym. Sci., Polym. Phys. Ed., 19, 921 (1981).

4. L. Larrondo and R. St. J. Manley, J. Polym. Sci., Polym. Phys. Ed., 19, 933 (1981).

5. J. Doshi and D. H. Reneker, J. Electrostatics, 35, 151 (1995).

6. J. Doshi, G. Srinivasan, and D. H. Reneker, Polymer News, 20, 206 (1995).

7. G. Srinivasan and D. H. Reneker, Polym. Int ., 36, 195 (1995).

8. Y. Aoki, L. Li, K. Nishimura, and Y. Arashiro, Macromolecules, 32, 1923 (1999).

9. R. Yamadera and M. Murano, J. Polym. Sci., A-1, 5, 2259 (1967).

10. S. S. Park, I. K. Kim, and S. S. Im, Polymer, 37, 2165 (1996).

11. G. A. Adam, J. A. Hay, I. W. Parsons, and R. N. Howard, Polymer, 17, 51 (1976). 